\title{
Being and Becoming Cosmopolitan:
}

\section{Higher Education and the Cosmopolitan Self}

\author{
Marianna Papastephanou ${ }^{1}$ \\ ${ }^{1}$ Department of Education, University of Cyprus, Nicosia, Cyprus \\ Correspondence: Marianna Papastephanou, Department of Education, University of Cyprus, PO Box 20537, Nicosia \\ 1678 Cyprus. E-mail: edmari@ucy.ac.cy
}

Received: April 3, 2013

Accepted: May 13, 2013

Online Published: May 14, 2013

doi:10.5430/ijhe.v2n2p184

URL: http://dx.doi.org/10.5430/ijhe.v2n2p184

\begin{abstract}
Much higher education (and teacher education in particular) aims to cultivate and promote cosmopolitan identity either through direct modular provisions or through student exchanges and other cultural encounters. The aim is to help students become cosmopolitan by organizing education in a way that is conducive to a specific conception of what counts as 'cosmopolitan'. However, the declarative element that is often present in such discourses and becomes most evident in one's relevant self-proclamation, i.e. 'I am a cosmopolitan' or 'we, cosmopolitans' has, justifiably and very pertinently, invited some important criticisms (e.g. by David Hansen). In this paper, I discuss those criticisms and register a possible way out of centripetal approaches to cosmopolitanism. To do so, I first explore the declarative element and its operations in Diogenes, M. Nussbaum, J. Waldron and K. A. Appiah's texts. Then, I turn to an alternative (and more ancient than the Diogenic) formulation of the cosmopolitan that allows, or so I hope, to escape the implications of self-indulgence, complacency and narrowness that are associated with fashionable self-idealizations of who the cosmopolitan might be.
\end{abstract}

Keywords: Nussbaum, Hansen, Cosmopolitan self, Appiah, Waldron, Diogenes, Globalization, Political education

\section{Introduction}

Cosmopolitan selfhood has attracted much attention within political educational discourse (see, for instance, Donald, 2007; Strand, 2010) to the point of becoming one of the fashionable objectives of educational ideality and normativity. Thus, political education aspires, amongst other things, to help students become cosmopolitan by organizing all stages of education in a way that is conducive to a specific conception of what counts as 'cosmopolitan subjectivity' (Papastephanou, 2012). This conception whose exposition here will be skeletal and limited to explanatory and justificatory purposes has, to some extent, been challenged by some social theorists and philosophers of education (Aboulafia, 2001; Benhabib, 2006; Pinar, 2009; Todd, 2009; Spector, 2011). But, for reasons of focus, the present article sets out only from some recent criticisms of the received conception of cosmopolitan selfhood that have been formulated by David Hansen (2008) and concern the problematic self-referential element of cosmopolitan discourse. In agreement with Hansen, I push those criticisms further and shift our perspective from the contemporary emphasis on the self-declarative element in cosmopolitan subjectivity to a third-person depiction of the cosmopolitan self through the qualifications of wisdom and goodness. Underlying the discussion that the article performs is the following stake: instead of setting the self in the centre; and instead of viewing the challenge the other presents to selfhood as issued from concentric circles surrounding the self, can we de-centre the cosmopolitan self through an ec-centric cosmopolitanism (Papastephanou, 2012) that makes higher demands upon the self than those made by the received view on cosmopolitan self-declaration?

Let me unpack the above. The standard (Note 1) view on cosmopolitan subjectivity proclaims 'cosmopolitan' the footloose individual who borrows cultural material from various and foreign sources. Such an individual takes pride in being thus constructed and in considering herself a 'cosmopolitan' person in a 'cosmopolitanized' world. This minimal and paradigmatic assumption acquires more flesh along the way, that is, when a whole set of theories of cosmopolitan subjectivity begins to emerge from it. Therefore, some theorists assume an easy passage from the cosmopolitan enjoyment of diversity and eagerness to know about the world to showing respect, even concern, for strangers; others take the just described cosmopolitan self as unconditionally rootless; yet another group of 
intellectuals believes that nothing within the concept of cosmopolitan subjectivity precludes rootedness, and so on and so forth.

The hypostatization of the cosmopolitan self also varies within the standard view, triggering disputes over who the exemplary cosmopolitan might be and inviting varying though corresponding pedagogies. For instance, some theorists following Julia Kristeva promote the dissident as emblematic of cosmopolitan selfhood and have been criticized for it (Varsamopoulou, 2009). More generally, philosophy and educational theory are often accused of maintaining an elitist or romantic image of cosmopolitan subjectivity and of identifying such a self with the estranged artist, the academic or the prominent philosopher. When philosophical discourse stands accused of maintaining an abstract, disembodied account of cosmopolitanism, other disciplines come in to 'correct' this only by empirically concretizing the cosmopolitan self as the embodied world traveler: 'the cosmopolitan characteristics of flexibility, adaptability and openness to difference and risk are not just cultural dispositions, but rather embodied performances of fitness and fitting in. Travellers literally embody cosmopolitanism' (Germann-Molz, 2006, p. 17). But, especially within this more practice- and context- oriented approach the initial and minimal core assumption of the footloose burgher as the self-declared cosmopolitan remains stronger than ever. Educationally, all this entails that the subjectivity to be cultivated in schools is more or less that of the 'cosmopolitan' traveler or learner of foreign cultural material. This carries on at the higher education level where students are urged to see themselves as cosmopolitans and be prepared to live and work abroad (Donald, 2007).

However, the declarative modality that manifests itself in such theories and becomes most evident in one's relevant self-proclamation, i.e. 'I am a cosmopolitan' or 'we, cosmopolitans' has, justifiably and very pertinently, invited some important criticisms on the part of some educational theorists (e.g. by David Hansen). I use such criticisms as a springboard to register what I regard as a way out of the self-indulgence, the complacency and the closure that are associated with fashionable self-idealizations of who the cosmopolitan might be. Prior to this, I explore the declarative element and its operations through gleanings of declarations coming from philosophers whose thought is representative of major traditions in political philosophy. Diogenes is thought to be the first to employ the self-declaration: I am a cosmopolitan. M. Nussbaum, J. Waldron, K. A. Appiah, D. Held and B. Ackerman employ self-declarations of cosmopolitanism in texts that reflect liberal, critical-theoretical and communitarian sensibilities, all philosophically-educationally influential in one way or other. This exploration prepares the ground for turning to an alternative formulation of the cosmopolitan - one that is more ancient than the Diogenic. I argue that one of Democritus's dicta encapsulates the cosmopolitan in a way that allows us, or so I hope, to escape the centripetal implications of the received view and to base our educational efforts on a theory of cosmopolitanism that makes higher demands upon the self.

\section{The Received View on Cosmopolitan Selfhood}

Much of the current discourse on cosmopolitanism operates within a subject-object philosophy of consciousness, where a self is confronted with the global. That this constitutes the starting point, the paradigmatic assumption, is evident in several theories, some of which begin or chime with the following idea: 'cosmopolitanism, at the very least, is a way of relating to the world' (Mendieta, 2009, p. 242). From then on, the pressing question is: what is the nature of that relationship? The answer echoes, in my view, a genealogy of cosmopolitanism that asserts a somewhat solipsist Cartesian, cogito construal of the relationship between the self and the world: 'from the Greek stoics, through the Medieval Christians with their universalistic Gospel, through the Byzantine Empire, to the Enlightenment philosophes, to be cosmopolitan was to think oneself citizen of the entire world' (ibid, emph added). The thinking subject considers herself a citizen of the entire world without fathoming this symbolic citizenship in terms of how others feel, experience and assess the accuracy and/or effects of the self-image that she maintains. The facile and convenient self-understanding is nowadays accompanied with an equally facile and convenient depiction of the world that contains many such individuals. The latter are served by many institutions, fora and global measures which give rise to an image of a cosmopolitanized world, i.e., a world of effected cosmopolitanism, a realized utopia of cosmopolitan citizens.

The received view on cosmopolitanism, a mainly culturalist view (Papastephanou, 2012), involves a specific account of the 'subject-object' relationship between the self and the world, an instantiation that puts together global self-awareness, mobility, hybridity and cultural enrichment. Within such basic premises, the standard outlook asserts that cosmopolitanism 'portrays the lifestyle of a globally conscious person, a cultivated citizen of the world, an individual with multiple identities or multi-national citizenships' (Strand, 2010, p. 231). An immediate objection concerns the fact that all people have multiple identities no matter whether they are conscious of it or not, multi-national citizens or not, cosmopolitan in their global commitments or not, aware of possibilities of politically 
activating those identities or not, etc. Identity is something quite different from consciousness, but this is the subject matter of another paper. What is important here, nevertheless, is the core assumption that cosmopolitanism is about globality, and the implicit assumption that this globality leads the self beyond or (in tension with) locality. Hence, it is extrapolated that 'similar to the in-between stranger - who is not confined by particular identities - the cosmopolitan self has greater allegiance to international communities and organizations than to local cultures and communities' (Marotta, 2010, p. 113).

Such assumptions about who counts as cosmopolitan are shared by opponents of cosmopolitanism too. The most extreme charge that they have directed at (self-declared) cosmopolitans is that they are parasites, that is, rootless and mobile selves who recognize no ethical debt and commitment to locality, move about for profit and depend on the rootedness of others - a rootedness that produces the diversity that they so value and from which they borrow what conditions them (Papastephanou, 2012). To this charge major thinkers of cosmopolitan discourse have responded: either by defending the rootlessness of the cosmopolitan self [or, at most, by granting rooted existence a cosmopolitan character only when rooted existence is immersed in global cities] (e.g. J. Waldron); or by conceding the rootedness of the cosmopolitan self generally (e.g. K. A. Appiah). But the conception of cosmopolitan selfhood as, simply, the person who enriches her lifestyle and existential choice with diverse cultural material, is happy about such enrichment and is thus led to respect and appreciation of foreign worlds is left untouched, along with the full ideological baggage that secures the high moral and political self-image of the complacent mobile burgher. For instance, as V. P. Marotta describes Waldron's position, 'it is only those who are "citizens of the world", or what he occasionally categorizes as the "cosmopolitan self", who can contribute to resolving global problems' (Marotta, 2010, p. 113). One wonders, of course, whether, instead of being the solution, such 'citizens of the world' are as much a part of the problems that the globe confronts as any other group of intellectuals upholding the image of a self-appointed soteriological collective subject might be. One needs only to consider a Foucault- or Agamben-inspired critique of cosmopolitan governmentality (such as is operative in Michael Peters' work) in order to realize that the picture of a cosmopolitan self as a global problem-solver is more problematic than it looks at first sight. Be that as it may, the dominant "cosmopolitan" self-understanding harbors a repressed crypto-utopianism that elevates global players to the status of the most able and rightful actors, a soteriological, utopian collectivity, in the global game of 'cosmopolitan' solutions regardless of local concerns. And it is then transferred rather uncritically into the educational context.

The extent of the influence that this conception of the cosmopolitan has exerted and the constructed tension between rootedness and rootlessness that it has given rise to can be illustrated by V. P. Marotta's following comment which explains how Waldron responds to communitarian criticisms of cosmopolitan subjectivity. The whole issue concerns the 'communitarian dismissal' versus the 'liberal appreciation' of nomadism - a dispute that reflects the more extreme quarrel about whether the cosmopolitan is a parasite or not. 'The rootlessness of the cosmopolitan self has been effectively captured by J. Waldron in his critique of identity politics in the USA', where Waldron deals with communitarian claims 'that the cosmopolitan self is nomadic, and that this self undermines the fixed and stable identities that constitute the modern subject. The outcome, according to the communitarians, is a lack of commitment and responsibility towards others' (ibid). Waldron (2000) challenges the communitarian account of the modern subject and replaces the communitarian assumption of a fixed self with the liberal assumption of a mixed-up self.

Waldron (ibid, p. 227) responds to the similar yet more offensive charge of cosmopolitans with parasitism that Roger Scruton has aired through reference to subjective experience - to the feelings of the cosmopolitan who is thus offended. He writes: 'personally, I feel the sting in the tail of [Scruton's] definition quite acutely - the cosmopolitan as parasite - because the charge of dabbling rootlessly in a plurality of cultures, each of which has taken generations or millennia to develop as a single living organism, seems to apply exactly to the idealized self-description I used in an article' (ibid). The self-description in question is repeated and defended in his more recent work too. The examples Waldron employs to illustrate the cosmopolitan self-description, e.g. that the cosmopolitan eats Chinese, wears clothes made in Korea, worships with the Book of Common Prayer, listens to arias by Verdi sung by a Maori diva on Japanese equipment, etc, assert that the cosmopolitan enriches her lifestyle with diverse cultural material. His line of defence, therefore, does not involve an alteration of the idealized self-description that both Scruton and Waldron take as definitional of the cosmopolitan; it involves, rather, an attack on identity politics. Waldron rejects both Scruton's attacks on the cosmopolitan as supposedly parasitic and the communitarian attacks on nomadism by presenting them as misrepresentations of the 'cosmopolitan self' that 'seem to hark back to, and be nostalgic for, Gemeinschaft relations' (Marotta, 2010, p. 113). And, to Waldron, as Marotta explains, 'these relations no longer reflect the "real communities" to which most of us belong' (ibid); in other words, they do not match our 'cosmopolitanized' world. 
Interestingly, these 'real communities' are illustrated through the kind of 'cosmopolitan' 'communal' exemplarity that has been criticized time and again for its elitism and intellectualism. For, as examples of such communities 'Waldron designates the international community of scholars, the scientific community, the human rights community, the artistic community' etc (ibid). Further, Waldron draws moral and political conclusions from the mere 'existence' of such communities and, in my view, crosses too hastily and arbitrarily the threshold that separates existential cultural enrichment/mobility from ethico-political commitment and action. Also, he argues that 'we need these global communities which incorporate diverse opinions and ideas to generate common solutions to common problems' (ibid). Yet, a more accurate and careful analysis of our cosmopolitanized world can show that neither the problems are commonly and evenly felt by all those affected by them nor can the solutions be as common and uniform as Waldron assumes.

Overall, Waldron portrays the cosmopolitan as a mixed-up self living in a mixed-up world and being pleased - rather than disconcerted - about his/her reliance on various cultures that offer the rich and diverse material which makes up the self. I have criticized this self-description and the culturalist, apolitical cosmopolitanism that it presupposes elsewhere (Papastephanou, 2012). What is of relevance here is that, in Waldron's case too, as in that of many other theorists, cosmopolitanism is a predicate of a specific selfhood, a significant part of one's self-understanding, and a manifestation of a subject who relates to objects that she encounters in the world and to which she is attracted.

Whilst Waldron responds thus to either conservative [e.g. Scruton's] or communitarian objections, K. A. Appiah, who also protests at the depiction of the cosmopolitan as a parasite, responds by reconciling rootedness and rootlessness as compatible rather than oppositional realities. Yet, both theorists (Waldron and Appiah) leave the received premises of cosmopolitan selfhood as a subject-object relation of cultural enrichment of one's life unaltered. This is how Appiah's response goes: 'We cosmopolitans face a familiar litany of objections. Some, for example, have complained that our cosmopolitanism must be parasitic' (Appiah, 1997, p. 618). As he explains, those who endorse this objection go on to ask where cosmopolitans could have gotten their various identities in a fully cosmopolitan world. 'Where, in other words, would all the diversity we cosmopolitans celebrate come from in a world where there were only cosmopolitans?' (ibid, emph added). Appiah's answer brings together rooted patriotism and cultural cosmopolitanism. There is a noticeable and remarkable touch of utopian possibility (positively meant here) in the way he formulates this coupling of patriotism and cosmopolitanism: the 'cosmopolitan patriot can entertain the possibility of a world in which everyone is a rooted cosmopolitan, attached to a home of one's own, with its own cultural particularities, but taking pleasure from the presence of other, different places that are home to other, different people' (ibid, emph added). The cosmopolitan subject of the possible world indicated by Appiah is not only pleasure-seeking but also potentially mobile. The cosmopolitan 'imagines that in such a world not everyone will find it best to stay in their natal patria, so that the circulation of people among different localities will involve not only cultural tourism (which the cosmopolitan admits to enjoying) but migration, nomadism, diaspora' (ibid).

All in all, Appiah's response is an interesting mediation between patriotism and cosmopolitanism. However, it remains trapped in the received view on cosmopolitanism, just like Waldron's response. It reproduces the confines of the modern understanding of cosmopolitanism as enrichment of one's identity through direct or indirect contact with diversity and jumps into conclusions about the potential ethico-political significance of such rich existential choices. In this way, Appiah's own insistence on cosmopolitanism as realization of one's ethical obligations becomes undermined by his culturalist approach to the notion of cosmopolitanism, but this is beside the point here. It is more important for the argument of this article that the culturalist conception of cosmopolitanism and its easy passage from the pleasure-seeking subject to the moral subject who shows respect for diversity are coupled with a reference to cosmopolitans as a quasi-community determined by a 'we', i.e. by an accomplished collective subjectivity that declares its presence, contests and demarcates its own discursive space and defends itself against charges by other camps.

\section{The Educated Self: Being and Becoming}

Much political educational discourse focuses on how to cultivate and promote the cosmopolitan identity that I have so far theorized as the received view and associated with a subject-object philosophy of consciousness. To this cosmopolitanism corresponds a specific selfhood/consciousness - one that relates to education in a reifying and conclusive sense, as Claudia Schumann (2012) explains from a third-generation Frankfurt School perspective. For, once such selfhood is envisioned and prepared educationally, we arrive at the cosmopolitically educated person, where already the '-ed' ending of the 'educated' points to a subjectivity of stability, closure and completion. As Klas Roth (2012) shows, Kant had already pointed out the difficulty of reaching an ideal that does not allow for facile approximations. Neglecting such caution, many contemporary thinkers assume that cosmopolitan selfhood is no 
longer an un-finished task, an open question, an ideal that is ever receding yet always desirable and in need of approximation. It is rather an accomplished reality, an effected and realized 'subjective' (privatized) utopia. Higher education and teacher education, in particular, to the extent that they invest in the political education of prospective teachers, have surrendered to an endless sloganeering about the globalized or cosmopolitanized world as a world of knowledge, opportunity, rootlessness and mobility. I will not delve into this unpleasant development, as it has already been criticized in the relevant literature (Rönnström, 2012; Hayden, 2012; Scheja, 2013). But I would like to add from the perspective of this article that, at the same time, this development turns students on by cultivating the self-image of the embodied cosmopolitan who can live and achieve within and across borders. In mobilizing libidinal energies, this self-image can be equalled only by the self-image of the Internet user and PC addict.

So long as cosmopolitan education of the hegemonic, culturalist kind can prove that it combats any alternative political education of 'monocultural coherence', it is usually welcomed and wholeheartedly endorsed by most teacher educators and students. The praised selfhood of the thus educated person answers demands that she be of this world (and not aspire to an imaginary citizenship of the world as should be and strive for its approximation). Ulrich Beck's methodological cosmopolitanism, for instance, which, as Corrado Matta (2013) pertinently explains, is expounded as an alternative to normative cosmopolitanism is precisely a case in point. For, it treats cosmopolitanism as an effected reality to which people should adapt and respond.

Deep down, all this operates: against any remote possibility of the self being answerable to currently disparaged utopianisms of a world as it should be; and in favour of a crypto-utopianization of the new-global-mobility-era as the accomplished best possible world, a cosmopolitanized world to which all must adapt themselves and respond to the changes that it effects. This is evident, for instance, in James Donald's question: what 'would cosmopolitan and multiculturally aware graduates be in the second decade of the $21^{\text {st }}$ century'? (2007, p. 296; latter emph added). It is also evident in the answer he gives - an answer that reflects not only his endorsement of the received view on cosmopolitanism but also that of most educational theorists. The answer that Donald gives to the above question transfers Waldron's guiding idea to education as follows: 'if the aim is to equip humanities graduates to survive and prosper in a diverse and globalized world, then developing their consciousness of living in a mixed-up world and having a mixed-up self does not seem a bad place to start' (ibid, p. 299). Again, as I have critiqued the culturalist emphasis of this answer elsewhere (Papastephanou, 2012) and with reference to Waldron, here I will confine my comments only to the issue of cosmopolitan consciousness and the self-image that it produces.

\section{Being Cosmopolitan and Self-Declared Cosmopolitanism}

As stated above, the changing consciousness of the future citizen has been associated with the tasks of a cosmopolitan teacher education or a cosmopolitan school curriculum. Is that the same as thinking oneself a cosmopolitan? Is one of the tasks of education to make students (or pupils) think of themselves as cosmopolitans? Should we educate teachers to educate the 'young' to see themselves as cosmopolitans in a cosmopolitanized world? I tackle this issue here indicatively and citationally by commenting on various related gleanings from depictions of cosmopolitan 'we' s and 'I' s.

Already in antiquity (and before Diogenes's famous statement 'I am a citizen of the world'), Socrates had declared his belonging to the world rather than exclusively to the city. Due to his overall philosophy, Socrates has, recently, been discussed as an exemplary figure of cosmopolitanism (Brown, 2000). With an eye to the Socratic ideal of an examined life, Martha Nussbaum has connected education for citizenship with three capacities: critical examination of oneself and one's tradition, the development of the narrative imagination, and seeing oneself as a cosmopolitan (Nussbaum, 2000, pp. 9-11). Significantly, the fact that seeing oneself as a cosmopolitan is of pivotal importance for Nussbaum is evident in her employment of the Diogenic declaration as a motto in her acclaimed essay on patriotism and cosmopolitanism (Nussbaum, 2002, p. 2) and in her further discussion of it as an invitation to people to think as world citizens (p. 7). But, as her 2002 introduction to the corresponding edition of For Love of Country shows, she is well aware of the risks involved in any complacent 'we' - be it the 'we' of compatriots threatened and alarmed by new realities or, by extension, that of more globally sensitive versions of any particular collectivity up to the most encompassing collectivity itself. And, beyond some contemporary theorists who seem to associate the cosmopolitan with a rather undemanding self-image (politically and ethically), Nussbaum does not give to the idea of 'seeing oneself as cosmopolitan' a primarily culturalist-descriptive (and thus indulgent and complacent, self-assuring and self-congratulatory) sense. Drawing on Stoic themes, she emphasizes, rather, the obligations that emanate from such a self-image, obligations that go beyond one's local commitments.

Arguably, there is a tendency on the part of some of her readers (sympathetic as well as critical) to interpret her plea for the development of the capacity to see oneself as cosmopolitan in terms of a declarative self-description. But, at 
least, Nussbaum raises some demands upon the self; hers is a cosmopolitanism that involves expectations of appropriate action, not only of verbal respect and existential (though objectifying) appreciation of what the other has to offer. As E. Mendieta (2009, p. 249) puts it, 'for Nussbaum, cosmopolitanism is not an abstract, philosophical stance, but rather a very practical and result-oriented attitude'. This is clearly manifest in the central position she gives to education. 'If we educate citizens to see themselves primarily as citizens of a world community, as opposed to members of narrow, special, chosen, and exceptional communities, then these citizens would be less likely to engage in the rituals of blood that are so indispensable to patriotism, and would instead be more responsive and engaged with the cultures and welfare of communities across the globe' (ibid). Despite the fact that Nussbaum's position on patriotism had been somewhat monolithic - something that she has also indicated in her more recent work on it (Nussbaum, 2008) - but which cannot be discussed here, it would be unfair to lose sight of the complexity of her idea of cosmopolitan self-regard compared to that of other theorists.

Likewise, it would be unfair to take Diogenes's declaration of himself as a citizen of the world out of its context and of its performative operations. Nevertheless, there is indeed a risk of self-congratulation in invitations to people to be cosmopolitan (like oneself). When meant and construed at face value, and then consolidated into a self-image, ready for educational cultivation, claims such as 'I am cosmopolitan [kosmou politēs]' or 'we, cosmopolitans' give the impression of something awkward, untrue to experience and self-indulgent (Hansen, 2008, p. 213).

Thus, the question is: can the self-declarative be rescued from the self-indulgent connotations or from the 'subject-object' relation, if we relativize the dimension of being that accompanies it by introducing the dimension of becoming? In his essay, 'Education for Global Citizenship', Appiah (2008) asserts the cosmopolitans' epistemic universalism but qualifies it with openness and inconclusiveness. He does so against those he calls 'counter-cosmopolitans' (most of whom are depicted as fundamentalist universalists claiming that their conception of the truth should be universally endorsed or even enforced). He writes, 'we cosmopolitans believe in universal truth, too, though we are less certain that we have it all already' (ibid, p. 95). In yet another affirmation of the first person plural of the cosmopolitan collectivity and its self-understanding, Appiah goes on to say that 'we cosmopolitans think we might learn something even from those we disagree with' (p. 97, emph added). However, though such formulations admittedly mitigate the consolidated being with a touch of as yet incomplete becoming, I find problematic that, once again, they emphasize a self prepared to benefit cognitively from otherness but, at the same time, a self who is ready to parade this qualification as yet another badge, an accomplishment that differentiates the self from all others and bestows upon the self a sense of moral and epistemic superiority.

What I find missing in this phenomenology of a 'subject-object' cosmopolitanism is put succinctly by Mendieta (2009, p. 254) (in a different context and for different reasons) as follows: 'we are always more and less than what we are imagined to be, which is why we must allow others to challenge our 'images' and 'imagination' of them, and conversely, to allow ourselves to correct our own self-understanding in light of those challenges'. I fear that, although much contemporary cosmopolitanism, even when influenced by popularized poststructuralist ideas, in theory, embraces indeed the above statement, in reality, it pays only lip service to it. For it lets its commitment to such openness be toned down (perhaps even annulled) by the 'subject-object' conceptual premises that underpin what counts as cosmopolitan in the first place (i.e., a self put centre stage, approaching alterity in cultural and cognitive terms, borrowing from it and returning to it the 'gift' by conceding to it a distant respect and a moralist tolerance). This can be shown if we take up again Appiah's response to the question: 'who the cosmopolitan might be?' and if the reader considers it alongside with what was said about Appiah's cosmopolitanism in a previous section.

Gerard Delanty (2006, p. 30) registers the definition of cosmopolitans that Appiah gave back in his 2005 book The Ethics of Identity as follows: 'cosmopolitans are people who construct their lives from whatever cultural resources to which they find themselves attached'. It is true that in such a conceptualization there is an 'interesting suggestion of culture as an on-going process of construction as opposed to being embodied in a particular way of life' (Delanty, 2006, p. 31). But there is also something else: within such a conception of the cosmopolitan self, the understanding of cosmopolitanism that precedes and grounds it limits cosmopolitanism to being a self-referential ideal of rich and multiple identity construction from which all moral, political and other such relational concerns might follow as possible implications - yet without having as such conceptual 'citizenship', so to speak, in what counts as cosmopolitan in the first place. In simpler words, for Appiah, at the conceptual level, cosmopolitan is the self who constructs her life by deriving material from a variety of cultural and cognitive objects that the world provides regardless of how this self treats others or views cosmos and regardless of the motivation for doing so. Thus, as we saw in the section where Appiah's cosmopolitanism was discussed together with Waldron's, cosmopolitanism lapses into a largely modern, hegemonic problematic about how the self benefits from cultural and cognitive variety and 
otherness to which it is expected to remain open precisely in order to remain in a position to continuously benefit from it. Ultimately, in Appiah's otherwise very important approach there is too much faith in the first person plural sense of cosmopolitan belonging, in the self-image that this produces in 'seeing oneself as a cosmopolitan' and in the ideas that the cosmopolitan subject entertains.

The following statement that I have gleaned from David Held can be considered as another such instance of a 'subject-object' philosophy of cosmopolitanism that secures a concomitant self-image that is also self-congratulatory of the self-declared 'we'. Held claims that 'those born after the Second World War are more likely to see themselves as cosmopolitans, to support the UN system and lend their support to the free trade system and the free movement of migrants' (Held, 2003, p. 469; emph added). Apart from being an interesting question for empirical research rather than a self-evident assertion, this view invites criticisms as to what counts as cosmopolitan and whether we should accept uncritically the self-description/self-image of post-War subjects as truly cosmopolitan. To adapt something that Mendieta says in a different context but which I consider very pertinent here: 'against a form of cosmopolitanism that is naïve about its own material conditions of possibility', philosophy must 'juxtapose a form of cosmopolitanism that reflects about its own material locatedness' (Mendieta, 2009, p. 243). Is the support to the United Nations and/or the support to free trade system and to free movement all it takes for one to be cosmopolitan? Is that the case, especially nowadays that the UN is largely criticized (Derrida, 2003, p. 111; Habermas, 2003, p. 39) for gradually becoming more like a paper tiger in the thrall of the strong global players rather than a truly justice-oriented organization of international right? Or is this self-regard just an unreflective surrender to what one's material locatedness allows one to see? Even if one could argue that the commitments singled out by Held are a necessary condition, are they also a sufficient one for justifiably claiming cosmopolitan subjectivities? True, it is ultimately a self (of a kind) who embraces a cosmopolitan ideal; but does this admission amount to the assumption that cosmopolitanism is a solipsistic matter of what ideas the thinking subject entertains and whether one sees herself as cosmopolitan?

If philosophy of consciousness is not the appropriate framework of cosmopolitanism, a possible alternative might be a philosophy of dialogue, offering what can be called 'an agreement perspective' on cosmopolitanism (Papastephanou, 2012). However, I believe that this perspective does not overcome the shortcomings of the subject-object approach. For example, Bruce Ackerman (1994, p. 535) takes another popular conception of cosmopolitanism (which, let us say parenthetically, is compatible with the culturalist conception), the one of cosmopolitanism as universalist agreement on certain values, and rightly perceives its dangers. But, in yet another instance of philosophical cosmopolitan self-declaration (with a confessional touch), he writes: 'I remain an unrepentant cosmopolitan. But there are risks lurking in this existential stance - a clear and present danger of pretentiousness, preciocity, and solipsism, as I find that others refuse to engage on the terms that ego finds so reasonable' (ibid). I believe that Ackerman here unwittingly touches on a question that proves again the limits of the 'rootless vs rooted' and 'identity vs difference' framework of cosmopolitan theorization. How do I, the rootless self, whose identity is cosmopolitan, cope with the radical difference of the rooted others, those who do not share what I find so reasonable? How do I cope with those cumbersome and fundamentalist others who enter dialogue with the view that they already possess the universal truth whereas I (as Appiah has also asserted) am open enough to assume that there is universal truth but I may not possess it and, therefore, I may learn it from others (though surely not from the fundamentalist fanatics about whom I only need to learn how to handle or how to cope with)? In a nutshell, the question is how different and independent egos would consent on maxims of action without each one of them solipsistically absolutizing one's own standpoint or fearing that the other will do so.

The answer I give to the above question presupposes an overcoming of the subject-object paradigm. It relies on acknowledging the significance of the relational sphere, beyond the monological framework that posits an individual who draws the ever expanding circles closer to self and thus remains the main reference point of cosmopolitanism. (Note 2) A shift from the monological to the relational would prioritize understanding cosmopolitanism as treatment of others over understanding it as agreement with them. Our diachronic and synchronic entanglement with others and with the whole world, and the indispensability of the role of the other for examining our life and imagining a vindicated cosmos, constitute a kind of cosmopolitan spectrality that puts cosmopolitan ideality in the appropriate perspective. Instead of worrying about how we, as incarnations (truly or supposedly) of the ideal cosmopolitan self-description, will cope with those that fail to meet the cosmopolitan standard; instead of worrying about how to convince them, we must let ourselves be haunted by the specters that our treatment of others and the environment has created. And we must make education a site for facing such spectrality. If we acknowledge the importance of questions about the treatment of cosmos, we realize that we need first to question whether we are indeed cosmopolitan instead of declaring our cosmopolitanism an indisputable fact. We should ask more deeply what it 
takes to be cosmopolitan, and then try to find out how others can deal with our becoming cosmopolitan in harkening to the demands of cosmos or whether they would converge in possibly common values. If we always assume that negotiation on world affairs is irrelevant or even prior to changes in our ways of treating others (or treating the environment) then we will never escape dilemmas such as the above. For one thing, dialogue is facilitated where there is trust and care - not in lip service but in reality, through provable and visible commitments to justice. One cannot trust another whose cosmopolitan declarations serve more her need to uphold a positive self-image rather than concrete, practical measures of changes in treating cosmos.

\section{Becoming Cosmopolitan: Wisdom and Goodness Beyond Self-Declared Cosmopolitanism}

What self-image of the teacher and the student do we encourage in the corresponding higher education? Who's cosmopolitan? Waldron's, Appiah's, Held's and Ackerman's declarative cosmopolitanisms, so diverse at first sight, but interestingly sharing much beneath the surface; just as the cosmopolitanism of those strangers who are cosmopolitan because they feel strange nowhere and everywhere; and just as the cosmopolitanism, culturalist or dialogical-legalist of many globalist thinkers, are amenable to an objection that can be drawn from David Hansen's more general reticence about one's self-bestowed characterization of being cosmopolitan. "There is something amiss, awkward, and untrue to experience for a person to claim, "I am a cosmopolitan", or to say about his or her community, "We are cosmopolitan"'. Indeed, the declarative modality points to a certain actuality of cosmopolitan identity, to being an accomplished task. Hansen (2008, p. 213) explains what is awkward about this with the following words: 'a cosmopolitan sensibility is not a possession, badge, or settled accomplishment. It is an orientation that depends fundamentally upon the ongoing quality of one's interactions with others, with the world, and with one's own self'. Based on this apposite and important criticism we have so far examined how it can guide our critical discussion of educating along the lines of well-known conceptualizations of cosmopolitan subjectivity. We have indicated that a mere contrast of 'being' to a vague 'becoming' cosmopolitan just by preserving the openness of inconclusive and never-ending learning (see the section on Appiah) does not stave off all the negative implications of the subject-object modality of cosmopolitan selfhood. In fact, it can be argued that self-declarations of cosmopolitanism display a tendency to what Richard Smith (2013) calls 'knowingness', i.e. a tendency to viewing the 'achievement' of knowledge as too smooth, too untroubled and ultimately too secure. (Note 3)

Would a more complex sense of becoming, e.g. the one associated with a deconstructive awareness of ruptures, dis-continuities, ambiguities and ambivalences that are constitutive of any identity give us a way out of this predicament? Perhaps we may easily sidestep the problem of the self-declarative with some qualifications and with the introduction of Derridean undecidability, an 'impossibility-yet-necessity' view on cosmopolitan identity, which can be made compatible with the notion of an inconclusive dialogue where we can let ourselves be influenced by the truth of the other. We may even add some Cavellian sense of openness and perfectibility. Important as all these possible paths may be, they are placed, in my view, within a politics of interpretation rather than of treatment and action, thus still operating within an exclusively dialogic model of cosmopolitanism. In this way, they connect our relation to language inseparably with the task of 'placing ourselves in the world' (Cavell, 1992, p. $53 \mathrm{emph}$ added), which, as I see it, perpetuates rather than breaking with the subject-object model of philosophizing about cosmopolitanism. What I am looking for, rather, is something more minimal (but, simultaneously, ethico-politically maximal) about the human self, something relatively disconnected from the first person (singular or plural: 'I', 'we', 'myself', 'ourselves') and, at the same time, more outspoken about the kinds of thought and action that can guide people as preconditions of cosmopolitanism. Such preconditions may constitute the axes of the positive and nuanced account of utopia that is necessary if cosmopolitanism is to be construed (at odds with the posited image of a supposedly cosmopolitanized world) as an ethical image that is indeterminate enough to lack a blueprint character but also determinate enough to be regulative even if in an ever-receding sense. The eccentric cosmopolitanism that I envision does not seek to place ourselves in the world but, rather, to displace us and commit us to images that are out of this world.

Diogenes's declaration, interpreted by Nussbaum as an invitation to people to see themselves as citizens of the world, can also be construed as a plea to join him in a citizenship out of his world; in other words, to join him in recognizing that the cosmopolitan citizen is a utopian citizen, a citizen of a world to come, a world that should come, or, better, a world that should be brought to existence by those who would aspire to be its citizens, yet they are not. But, as Diogenes's self-proclamation is inextricable from the performative purposes that it had served when firstly uttered, and it is a self-proclamation after all, let us go even further back in time. Let us consider a third-person ideal description of the cosmopolitan which is more ancient than the Cynic. Democritus (b. 460 BC) had stated roughly 50 years before Diogenes that 'any land is traversible by the wise; to the good self the whole world is homeland' (frg 247, emphasis mine). (Note 4) Although traversibility points at first sight to an association of cosmopolitanism with 
mobility and rootlessness, this statement is more interesting than some contemporary approaches to footloose cosmopolitanism because its idea of traversibility is accompanied and qualified by the intellectual (wisdom) and ethical (goodness) precondition. Surely, one may object that the role of wisdom and goodness may be unclear as their semantic content is unspecified. All of us have an understanding of the terms (as designating unattained idealities) that makes them usable in the first place, though all of us acknowledge that defining the terms or delineating their province is a daunting task of debatable conclusions. But this is precisely the point: wisdom and goodness are not prescriptively introduced in cosmopolitan discourse as recipes that if one follows them she will become cosmopolitan. Rather, the third-person description of the wise and the good (hazy as it is in its minimal determinacy) introduces a distance between the I (we) and the Other (the wise and good that I am not, but I would like to be) and between the real and the ideal. This distance keeps away the danger of cosmopolitanism as self-proclamation. Thus, it adds an important dimension to ec-centric cosmopolitanism as a de-centering process, as a diversion from the self-centeredness of the contemporary globalized self and from the self-congratulatory, soothing self-image of the self-declared cosmopolitan. It also keeps away associations of accomplishment because it sets demands on selfhood such as wisdom and goodness which, thankfully, the Western, 'cosmopolitanized' world still regards as daunting (or, at least, shies away from claiming that it meets them already). Although citizens of the globalized world often raise claims to cosmopolitan selfhood, seldom do they feel comfortable with claims of having achieved the status of the wise and the good. They would not declare 'we, the wise and good' with the same ease that they declare 'we, cosmopolitans'.

\section{Conclusion}

Wisdom and goodness and the awe they inspire supply the missing link with action. For, the passage to action is really absent in the received view on cosmopolitanism: the emphasis on never-ending, formative dialogue does not specify what the self-declared 'cosmopolitans' deem wise and ethical to do in a world that celebrates diversity. The 'cosmopolitanized' world indulges itself in the positive moral self-image that the proclamation of cosmopolitan commitment bestows upon the person. Yet, at the same time, the supposedly global citizens accept with too few questions the unethical role of their governments in various conflicts, the ongoing destruction of the environment and the failure to take the appropriate measures, as well as the letting of people die of hunger, lack of water and medication in many 'non-developed' countries. Against this situation, wisdom and goodness raise expectations of thought and action that unsettle the convenient conception of the cosmopolitan as simply the person who, rooted or rootless, enriches herself with cultural material from diverse localities and shows only respect to such diverse providers of existential options and of marketplaces of goods, ideas and lifestyles.

Likewise, the elitism that is usually associated with the graduate, the academic, the traveler as such or the footloose manager can be challenged by the fact that neither wisdom nor goodness are inextricably tied with the Eurocentric notion of the educated and well-fed burgher: apparently paradoxically, the cognitive and affective significance of learning about the other can often be grasped and then expressed by people who have developed a self-less and inquisitive personality regardless of ability or inability to 'prove' their cosmopolitanism by means of degrees, journeys and other such tokens of mobility and encyclopedic knowledgeability. Furthermore, the inconclusive character of the ideals of wisdom and goodness can be transferred to the ideal of 'being' cosmopolitan and make the latter's inconclusiveness stand out too, thus giving to 'becoming' its due. Thus, this article has not questioned the significance of cultivating culturally outward sensibilities (of of organizing global exchanges of students and academics) in higher education. It has only stressed the importance of viewing all these endeavors in more theoretical depth and of making the educating/educated self more aware of the higher demands that cosmopolitan ideality presents for higher education.

There are surely more applied questions about how all this may translate into concrete terms of teacher education, student learning or curricular design, some of which may involve significant empirical research. Such questions and answers concentrate on what captures the practical cultivation of epistemic virtues, reflective mindsets and ethical dispositions based on what we so far know about student learning. But all this is set aside here, since the focus is on the normative-theoretical redirection that may guide empirical research in different paths beyond established theoretical patterns. The article does not aim to cover the empirical ground, for which, nevertheless more than an extra paper would be required. The normative-theoretical conclusion is, rather, that education should acknowledge that the cosmopolitan may not be the one who feels stranger everywhere and nowhere but the one whose ethico-politically heightened consciousness opens her up to a world-to-come. Unhappy in a cosmopolitanized (qua globalized) world, such a person does not take pride in declaring herself a cosmopolitan but admits the desire to be so, the desire to approximate the kind of goodness and wisdom - always hazy because always seen from a distance that makes us cross internal borders. Education should focus on the cultivation of the self whose desire for an as yet 
unreached (and perhaps unreachable) wisdom and goodness dis-places selfhood and moves it toward an ec-centric citizenship of an as-yet no place (topos).

\section{References}

Aboulafia, M. (2001). The Cosmopolitan Self: George Herbert Mead and Continental Philosophy. Urbana and Chicago: University of Illinois Press.

Ackerman, B. (1994). Rooted Cosmopolitanism. Ethics, 104 (3): 516-535. http://dx.doi.org/10.1086/293628

Appiah, K. A. (1997). Cosmopolitan Patriots. Critical Inquiry, 23 (3) (1997): 617-639. http://dx.doi.org/10.1086/448846

Appiah, K. A. (2005). The Ethics of Identity. Princeton: Princeton University Press.

Appiah, K. A. (2008). Education for Global Citizenship. In: D. Coulter and J. Wiens, (eds.), Why Do We Educate? Renewing the Conversation. Massachusetts: Blackwell, 83-99. http://dx.doi.org/10.1002/9781444307214.ch6

Benhabib, S. (2006). Another Cosmopolitanism. Oxford: Oxford University Press. http://dx.doi.org/10.1093/acprof:oso/9780195183221.001.0001

Brown, E. (2000). Socrates the Cosmopolitan. Stanford Agora: an Online Journal of Legal Perspectives, 1 (1): 74-87.

Cavell, S. (1992). The Senses of Walden. Chicago: University of Chicago Press. http://dx.doi.org/10.7208/chicago/9780226075013.001.0001

Delanty, G. (2006). The Cosmopolitan Imagination: critical cosmopolitanism and social theory. The British Journal of Sociology, 57 (1): 25-47. http://dx.doi.org/10.1111/j.1468-4446.2006.00092.x PMid:16506995

Derrida, J. (2003). Autoimmunity: Real and Symbolic Suicides: a dialogue with J. Derrida. In Borradori, G. (ed) Philosophy in a Time of Terror. Chicago: The University of Chicago Press, 85-136. PMid:16241312

Donald, J. (2007). Internationalisation, Diversity and the Humanities Curriculum: Cosmopolitanism and Multiculturalism Revisited. Journal of Philosophy of Education 41 (3): 289-308. http://dx.doi.org/10.1111/j.1467-9752.2007.00572.x

Germann-Molz, J. (2006). Cosmopolitan Bodies: Fit to Travel and Travelling to Fit. Body and Society 12 (3): 1-21. http://dx.doi.org/10.1177/1357034X06067153

Gregoriou, Z. (2003). Resisting the Pedagogical Domestication of Cosmopolitanism: From Nussbaum's Concentric Circles of Humanity to Derrida's Aporetic Ethics of Hospitality. Philosophy of Education Yearbook 2003: 257-266.

Habermas, J. (2003). Fundamentalism and Terror: a dialogue with J. Habermas. In Borradori, G. (ed) Philosophy in a Time of Terror. Chicago: The University of Chicago Press, 25-44. PMid:15115009

Hansen, D. (2008). Education Viewed Through a Cosmopolitan Prism. Philosophy of Education Yearbook 2008: 206-214.

Hayden, M. (2012). Arendt and cosmopolitanism: the human conditions of cosmopolitan teacher education. Ethics and Global Politics 5 (4): 239-258.

Held, D. (2003). Cosmopolitanism: Globalisation Tamed? Review of International Studies 29: 465-480. http://dx.doi.org/10.1017/S0260210503004650

Marotta, V. P. (2010). The Cosmopolitan Stranger. In: S. van Hooft, W. Vandekerckhove (eds). Questioning Cosmopolitanism, Studies in Global Justice. Amsterdam: Springer, 105-120. http://dx.doi.org/10.1007/978-90-481-8704-1_7

Matta, C. (2013). Cosmopolitanism, social science and teacher education. (Forthcoming, manuscript in my possession).

Mendieta, E. (2009). From Imperial to Dialogical Cosmopolitanism. Ethics and Global Politics 2 (3): 241-258.

Nussbaum, M. (2000). Cultivating Humanity: A Classical Defense of Reform in Liberal Education. Cambridge, Mass: Harvard University Press. 
Nussbaum, (2002). 'Patriotism and Cosmopolitanism' In: M. Nussbaum and J. Cohen (eds). For Love of Country? Boston: Beacon Press.

Nussbaum, M. (2008). Toward a Globally Sensitive Patriotism. Daedalus, 137 (3): 78-93. http://dx.doi.org/10.1162/daed.2008.137.3.78

Papastephanou, M. (2012). Thinking Differently About Cosmopolitanism: Theory, Eccentricity and a Globalized World. Boulder, USA: Paradigm Publishers.

Peters, P. (2013). Problematizing liberal cosmopolitanisms: Foucault and neoliberal cosmopolitan Governmentality. (Forthcoming; manuscript in my possession after personal communication with the author).

Pinar, W. (2009). The Worldliness of a Cosmopolitan Education: Passionate Lives in Public Service. New York: Routledge.

Rönnström, N. (2012). From globalist to cosmopolitan learning: on the reflexive modernization of teacher education. Ethics and Global Politics 5 (4): 193-216.

Roth, K. (2012). A cosmopolitan design of teacher education and a progressive orientation towards the highest good. Ethics and Global Politics 5 (4): 259-279.

Scheja, M. (2013). Cosmopolitan student learning in teacher education- cosmopolitan visions, approaches to learning and the disposition to understand for oneself. [Online] Available: http://www.cesam.su.se/polopoly_fs/1.123465.1360576412!/menu/standard/file/Max\%20Scheja.pdf

Schlaifer, R. (1936). Greek Theories of Slavery from Homer to Aristotle. Harvard Studies in Classical Philology, 47: 165-204. http://dx.doi.org/10.2307/310574

Schumann, C. (2012). A Boundedness beyond reification: cosmopolitan teacher education as critique. Ethics and Global Politics 5 (4): 217-237.

Smith, R. (2013). Re-reading Plato: the slow cure for knowledge. In: M. Papastephanou, T. Strand and A. Pirrie (eds). Philosophy as a Lived Experience. Berlin: Lit Verlag (forthcoming).

Spector, H. (2011). The Question of Cosmopolitanism: An Essay Review. Education Review 14 (2): 1-13.

Strand, T. (2010). The Making of a New Cosmopolitanism. Studies in Philosophy and Education 29 (2010): 229-242. http://dx.doi.org/10.1007/s11217-009-9161-3

Todd, S. (2009). Toward an imperfect education: Facing humanity, rethinking cosmopolitanism. Boulder, CO: Paradigm Publishers.

Varsamopoulou, E. (2009). The Idea of Europe and the ideal of Cosmopolitanism in the Work of Julia Kristeva. Theory, Culture and Society 26 (1): 24-44. http://dx.doi.org/10.1177/0263276408099014

Waldron, J. (2000). What Is Cosmopolitan? The Journal of Political Philosophy, 8 (2): 227-243. http://dx.doi.org/10.1111/1467-9760.00100

Note 1. On what grounds this view can be seen as standard or received, see Papastephanou (2012).

Note 2. Zelia Gregoriou (2003) raises similar objections to such operations of concentric cosmopolitanism yet from a different perspective.

Note 3. Smith's educational-philosophical notion of knowingness has not yet been employed as a conceptual tool for critiquing facile views on cosmopolitanism. But, as much as this is relevant to this paper it needs to be dealth with elsewhere for reasons of space.

Note 4. In the Greek original: andri sophō pasa gē vati; Psychēs gar agathēs patris o xymbas cosmos. The phrase is also mentioned by R. Schlaifer (1936, p. 169). 